Journal of Computer Science 8 (6): 879-890, 2012

ISSN 1549-3636

(C) 2012 Science Publications

\title{
An Adaptive Neuro-Fuzzy Inference System Based Modeling for Corrosion-Damaged Reinforced HSC Beams Strengthened with External Glass Fibre Reinforced Polymer Laminates
}

\author{
Balasubramaniam, V., P.N. Raghunath and K. Suguna \\ Department of Civil and Structural Engineering, \\ Annamalai University, Chidambaram-608 001, India
}

\begin{abstract}
Problem statement: This study presents the results of ANFIS based model proposed for predicting the performance characteristics of reinforced HSC beams subjected to different levels of corrosion damage and strengthened with externally bonded glass fibre reinforced polymer laminates. Approach: A total of 21 beams specimens of size 150, 250×3000 mm were cast and tested. Results: Out of the 21 specimens, 7 specimens were tested without any corrosion damage (R-Series), 7 after inducing 10\% corrosion damage (ASeries) and another 7 after inducing 25\% corrosion damage (BSeries). Out of the seven specimens in each series, one was tested without any laminate, three specimens were tested after applying $3 \mathrm{~mm}$ thick CSM, UDC and WR laminates and another three specimens after applying 5mm thick CSM, UDC and WR laminates. Conclusion/Recommendations: The test results show that the beams strengthened with externally bonded GFRP laminates exhibit increased strength, stiffness, ductility and composite action until failure. An Adaptive Neuro-Fuzzy Inference System (ANFIS) model is developed for predicting the study parameters for input values lying within the range of this experimental study.
\end{abstract}

Key words: An Adaptive Neuro-Fuzzy Inference System (ANFIS), Fibre Reinforced Polymer (FRP), Two bars Ribbed Tor Steel (RTS), Chopped Strand Mat (CSM)

\section{INTRODUCTION}

Corrosion of steel rods embedded into reinforced cement concrete is a great challenge for maintenance Engineers. Restoration of corroded structural members to original or better level of performance is a necessity for keeping old structures in service. Although many techniques exist for repair and rehabilitation of corroded reinforced concrete structures, Fibre Reinforced Polymer (FRP) provides an effective material for strengthening both flexural and compression members. Fibre Reinforced Polymer as an external reinforcement may be applied for strengthening beams, columns, slabs and masonry walls. Application of FRP for strengthening corrosion damaged beams is a viable technique for improving their strength and post-yield load deflection characteristics. The electrical potential of steel determines its corrosion tendency with respect to other materials. In addition, the material properties of steel often pre-formulate microscopic and localized anodic and cathodic regions (Bentur et al., 1997).
There are several situations that would increase the Iikelihood of microcell corrosion in steel (Bentur et al., 1997; Al-Sulaimani et al., 1990; Lee et al., 1997; Mangat and Elgarf, 1999). In galvanic corrosion, two dissimilar metals of the electromotive (or galvanic) series having direct contact in an ambient environment would create differential electrical potential and result in corrosion of the metal located at the upper position of the electromotive series. Uomoto et al. (1984) and Almusallam et al. (1996) subjected several small RC beams reinforced with a single $16 \mathrm{~mm}$ rebar to accelerated corrosion using an impressed current and found that rebar corrosion has pronounced effect on the structural strength of RC beams than it does on the yield strength of the rebar. This result was attributed to the loss of bond between rebar and concrete due to cracking in concrete resulting from the expansive forces of the corrosion products. All the specimens were tested in flexure after corrosion and the results showed that un-corroded beams failed in flexure; while corroded beams exhibited a shear-bond failure at a load range of $67-95 \%$ as compared to un-corroded beams. It was concluded that the critical point in strength degradation

Corresponding Author: Balasubramaniam, V., Department of Civil and Structural Engineering, Annamalai University, Chidambaram-608 001, India 
occurs when longitudinal cracks form along the steel bars. Umoto (Andrade et al., 1990) suggested that increasing the concrete cover decrease diffusion of chloride ions and prevents crack formation along the reinforcing bars.Soudki (Hussain et al., 1995) revealed that CFRP laminates successfully confined the corrosion cracking. All the strengthened beams exhibited increased stiffness over the unstrengthened specimens and marked increases in the yield and ultimate strength. The CFRP strengthening scheme was able to restore the capacity of corrosion damaged concrete beams up to $15 \%$ mass loss.

Many researchers have shown that concrete repair using FRP laminates is very successful in restoring or increasing the strength of concrete members. A further promising aspect of FRP repair is the prevention of deterioration due to rebar corrosion by confinement of the concrete member (Masoud et al., 2001; Sherwood and Soudki, 1998a; 1998b). By strengthening concrete members with FRP laminates, concrete spalling and cracking caused by the expansive forces of the corrosion products may be delayed or even prevented.

The results of different studies discussed above strongly suggest that the corrosion cracking around the steel rebar is a fundamental component contributing to the loss of structural strength. This implies that if corrosion cracking can be prevented, or at least decreased, a certain degree of structural strength may be maintained in a corroding RC beam. This research derives such a relationship based on experimental data.

Experimental programme: The experimental program involved casting of 21 beam specimens, subjecting them to predetermined level of corrosion damage, applying GFRP plating of appropriate thickness and testing on loading frame. This chapter presents detailed information on the experimental investigation.

\section{MATERIALS AND METHODS}

Cement concrete: Cement concrete having a compressive strength of 63.64MPa was used for casting the beam specimens. The concrete for casting was procured in the form of ready mixed concrete having a mix ratio of 1:1.64:2.37:0.35 (cement: F.A.: C.A.: Water). Hyperplasticiser (Glenium B23) was used at a dosage of $0.80 \%$ by weight of binder.

Steel: Steel rods used for reinforcing the beams had tensile yield strength of 456.51 MPa. Two bars Ribbed Tor Steel (RTS) having $12 \mathrm{~mm}$ diameter were used for tensile reinforcement. Two bars having $10 \mathrm{~mm}$ diameter were used as hangers. Two-legged shear stirrups having $8 \mathrm{~mm}$ diameter were placed at $150 \mathrm{~mm}$ $\mathrm{c} / \mathrm{c}$ along the span of beam.

Fibre Reinforced Polymer (FRP): Three types of Glass Fibre Reinforced Polymer plates were used for the experimental investigation, viz., (i) Chopped Strand Mat (CSM), (ii) Uni-Directional Cloth, (iii)Woven Rovings. Sample fibre configurations are shown in Fig. 1.

Mechanical properties of the FRP laminates are listed in Table 1. Mechanical properties of the resin used for the FRP are listed in Table 2.

Specimen preparation: 21 beam specimens having dimensions of $150,250 \times 3000 \mathrm{~mm}$ were cast on masonry moulds prepared with polymer sheet lining on sides. The curing of specimens was carried out for 28 days in a standard manner. Out of the 21 specimens, 7 specimens were tested without any corrosion damage (R-Series), 7 specimens after inducing 10\% corrosion damage (A-Series) and another 7 specimens after inducing 25\% corrosion damage (B-Series). Out of the seven specimens in each series, one was tested without any laminate, three specimens were tested after applying $3 \mathrm{~mm}$ thick CSM, UDC and WR laminates and another three specimens after applying $5 \mathrm{~mm}$ thick CSM, UDC and WR laminates. Table 3 shows the designation of specimens and their specifications.

Inducing corrosion damage to the specimens: Corrosion damage was induced by electro-chemical process by passing predetermined quantity of electrical charge through the steel rods. This was accomplished by connecting the steel rods to an electrical circuit and measuring the potential difference (voltage) and charge transfer through voltmeter and ammeter respectively. The specimens needing corrosion damage were immersed in a pond of electrolytic solution containing $3.5 \%$ sodium chloride salt $(\mathrm{NaCl})$ dissolved in water. The reinforcement bars were connected to the positive pole of electrical power supply. The negative side of the circuit was connected to a metal plate (the cathode). This initiated corrosion in the steel bars of the reinforced concrete beam. The specimens were incorporated with a direct current power supply with an output of $11 \mathrm{amps}$ thereby achieving theoretical steel weight loss of 10 and $25 \%$. According to Faraday's law:

$$
\Delta \mathrm{w}=\frac{\text { Am.I.t }}{\text { z.F }}
$$

Where:

$\Delta \mathrm{w}=$ Mass loss due to corrosion

$\mathrm{A}_{\mathrm{m}}=$ Atomic mass of iron $(55.85 \mathrm{~g})$ 
Table 1: Properties of Glass Fibre Reinforced Polymer (GFRP)

\begin{tabular}{lcccc}
\hline $\begin{array}{l}\text { Type of fibre } \\
\text { in GFRP }\end{array}$ & $\begin{array}{l}\text { Thickness Tensile strength } \\
(\mathrm{mm})\end{array}$ & $\begin{array}{l}\text { Ultimate } \\
\text { elongation }(\%)\end{array}$ & $\begin{array}{l}\text { Elasticity } \\
\text { modulus (MPa) }\end{array}$ \\
\hline Chopped strand mat & 3 & 126.20 & 1.69 & 7467.46 \\
Chopped strand mat & 5 & 156.00 & 1.37 & 11386.86 \\
Uni-directional cloth & 3 & 446.90 & 3.02 & 13965.63 \\
Uni-directional cloth & 5 & 451.50 & 2.60 & 17365.38 \\
Woven rovings & 3 & 147.40 & 2.15 & 6855.81 \\
Woven rovings & 5 & 178.09 & 1.98 & 8994.44 \\
\hline
\end{tabular}

Table 2: Mechanical properties of the resin

\begin{tabular}{lr}
\hline Property & Value \\
\hline Density $\left(\mathrm{kg} / \mathrm{m}^{3}\right)$ & 1100.0 \\
Elasticity Modulus $(\mathrm{GPa})$ & 20.0 \\
Shear Modulus $(\mathrm{GPa})$ & 8.0 \\
Poisson's Ratio & 0.4 \\
Tensile Strength $(\mathrm{MPa})$ & 30.0 \\
Compressive Strength $(\mathrm{MPa})$ & 110.0 \\
Shear Strength $(\mathrm{MPa})$ & 30.0 \\
Tensile Strain at Break $(\%)$ & 5.0 \\
Water Absorption: 7 -days $-25^{\circ} \mathrm{C}(\%)$ & 0.1 \\
\hline
\end{tabular}

Table 3: Specimen designation

\begin{tabular}{llll}
\hline $\begin{array}{l}\text { Specimen } \\
\text { designation }\end{array}$ & $\begin{array}{l}\text { Corrosion } \\
\text { damage }(\%)\end{array}$ & $\begin{array}{l}\text { Type of GFRP } \\
\text { laminate }\end{array}$ & $\begin{array}{l}\text { Thickness of } \\
\text { laminate }(\mathrm{mm})\end{array}$ \\
\hline R0 & 0 & - & - \\
RCSM3 & 0 & CSM & 3 \\
RCSM5 & 0 & CSM & 5 \\
RUDC3 & 0 & UDC & 3 \\
RUDC5 & 0 & UDC & 5 \\
RWR3 & 0 & WR & 3 \\
RWR5 & 0 & WR & 5 \\
A0 & 10 & - & - \\
ACSM3 & 10 & CSM & 3 \\
ACSM5 & 10 & CSM & 5 \\
AUDC3 & 10 & UDC & 3 \\
AUDC5 & 10 & UDC & 5 \\
AWR3 & 10 & WR & 3 \\
AWR5 & 10 & WR & 5 \\
B0 & 25 & - & - \\
BCSM3 & 25 & CSM & 3 \\
BCSM5 & 25 & CSM & 5 \\
BUDC3 & 25 & UDC & 3 \\
BUDC5 & 25 & UDC & 5 \\
BWR3 & 25 & WR & 3 \\
BWR5 & 25 & WR & 5 \\
\hline
\end{tabular}
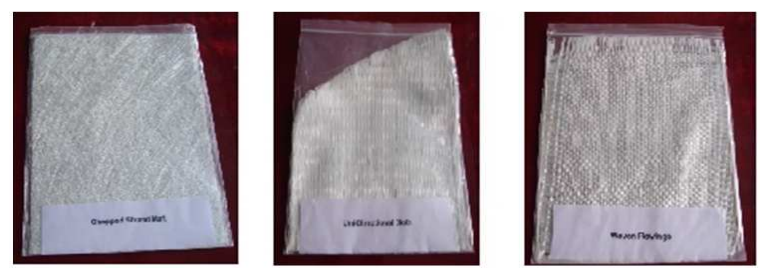

Fig. 1: Sample fibre configurations

I = Corrosion current in amps

$\mathrm{T}=$ Time since corrosion initiation (sec)

$\mathrm{Z}=$ Valence (assuming that most of rust product is due to $\mathrm{Fe}(\mathrm{OH})_{2}, \mathrm{Z}$ is taken as 2)

$\mathrm{F}$ = Faraday's constant [96487 coulombs (g/equivalent)]

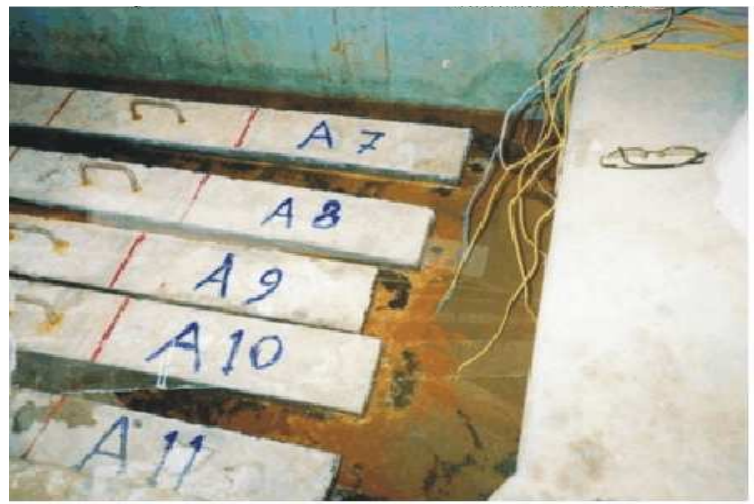

Fig. 2: Specimens in corrosion tank

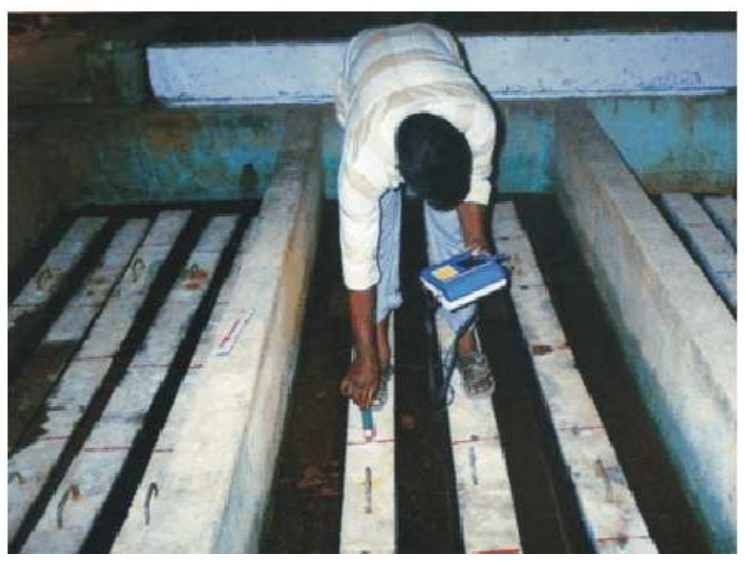

Fig. 3: Half-cell potential readings on beams

Bonding FRP plates to beam soffit: After subjecting the specimens to required level of corrosion in brine solution, the specimens were removed from the tank, cleaned. FRP laminate of required type and thickness was bonded to the soffit of beams using two - part epoxy adhesive. Figure 2 shows beam specimens placed in corrosion tank. Figure 3 shows half cell potential readings being taken on the beam specimens subjected to corrosion.

Test set-up and procedure: The beam was placed in position and the points for placing the dial gauges and points for applying the load were marked. The beam was simply supported with an effective span of $2800 \mathrm{~mm}$. The rectangular beam was kept upright with the supports touching the soffit of the beam. The loading points were located on the top of the beam at a distance of $1 / 6$ of span measured on either side of its centre point. The deflections were measured at mid-span and loading points using mechanical dial gauges of $0.01 \mathrm{~mm}$ accuracy. 


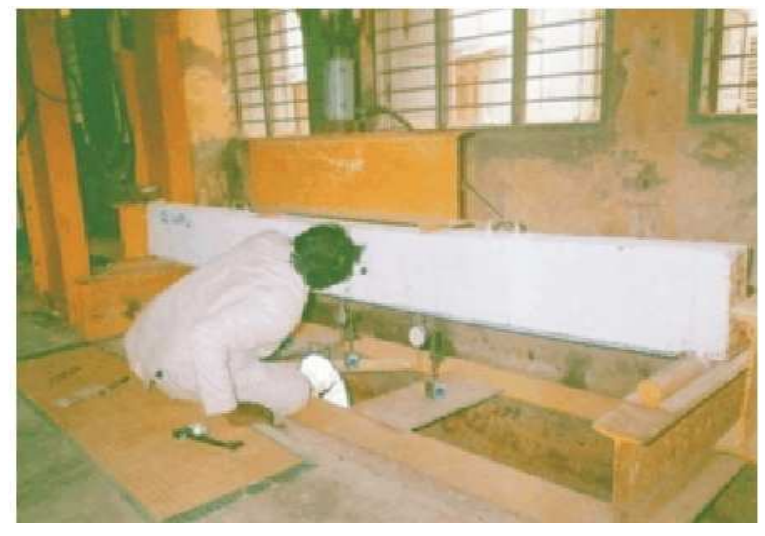

Fig. 4: Fixing gauges for testing beam specimens

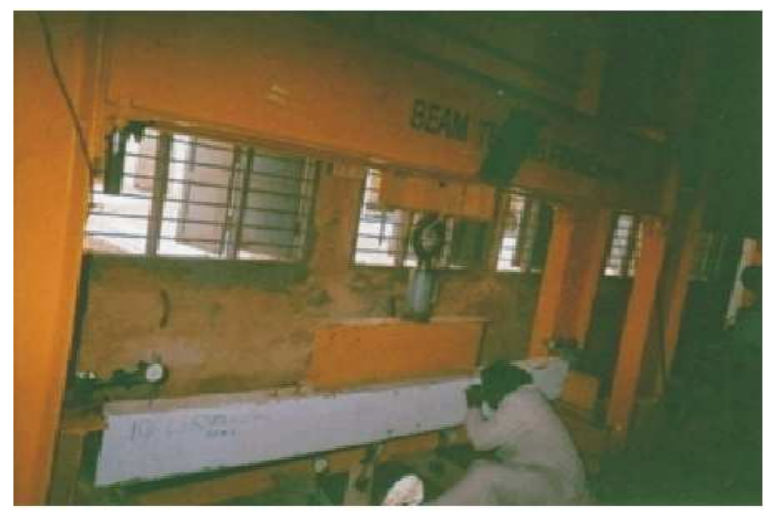

Fig. 5: Test setup for beam specimens

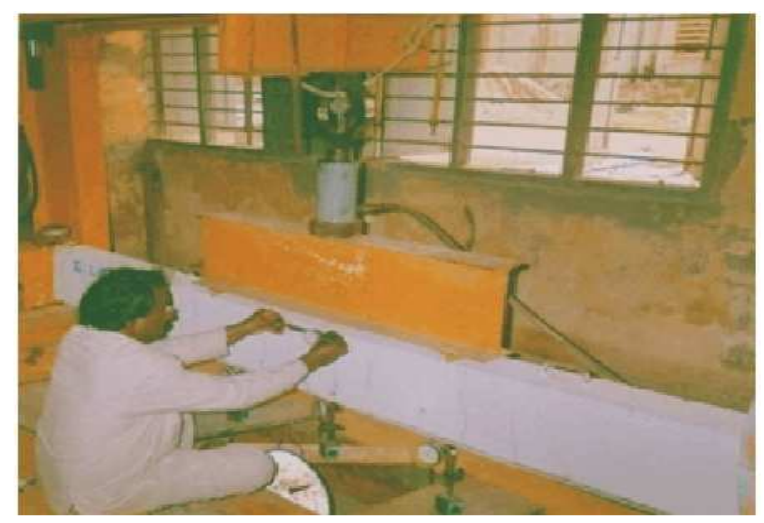

Fig. 6: DEMEC Measurement for surface strains

The crack widths were measured using crack deflection microscope with a least count of $0.02 \mathrm{~mm}$. The support lines from the bottom of the beam were traced to the top of the beam. The centre of the width of the beam above the support was marked for positioning the outer dial gauges for measuring the curvature of the beam.

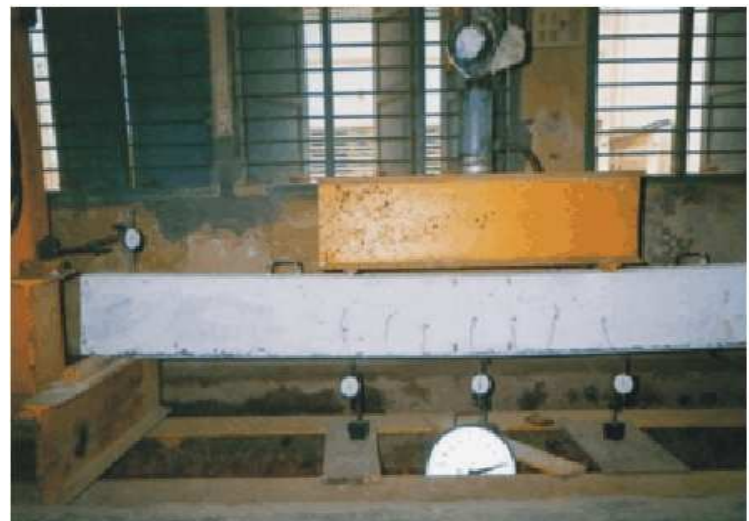

Fig. 7: Crack patterns in tested specimens

One more line was drawn parallel to the line above the supports at a distance of $10 \mathrm{~cm}$ towards the centre from each support. The middle points of these lines across the beam width were marked for positioning the inner dial gauges for measuring the curvature of the beams.

One more steel dial gauge to measure the final deflection of the beam after failure was positioned at the centre and connected by a thread from a point along the centre line traced on the bottom of web. To measure the strain, DEMEC gauge was used. In order to take the readings, DEMEC pins were fixed. The loading was applied through a loading jack in stages of $250 \mathrm{~kg}$. The beams were tested till failure and the corresponding loads and deflections were noted. Figure 4-7 shows sequence of testing of the beam specimens.

\section{RESULTS AND DISCUSSION}

Results obtained from the experimental investigation are presented. The essential parameters of study were the moment-curvature behaviour, first crack load, first crack deflection, yield load, yield deflection, ultimate load, ultimate deflection, deflection ductility, energy ductility and energy absorption of the beams.

Moment-curvature behaviour: Figure 8 shows moment-curvature curves for all the twenty one specimens. Moment-curvature curves indicate that the performance levels are lowered by the level of corrosion damage. Application of FRP plates increased the performance levels of the beams.

The moment-curvature diagram shows reference beam with $5 \mathrm{~mm}$ thick UDC plating (RUDC5) to be the best performer. Beam having 10\% corrosion damage and strengthened with $5 \mathrm{~mm}$ thick UDC plate (AUDC5) performed very close to RUDC5, only to fail at much lower moment level. 


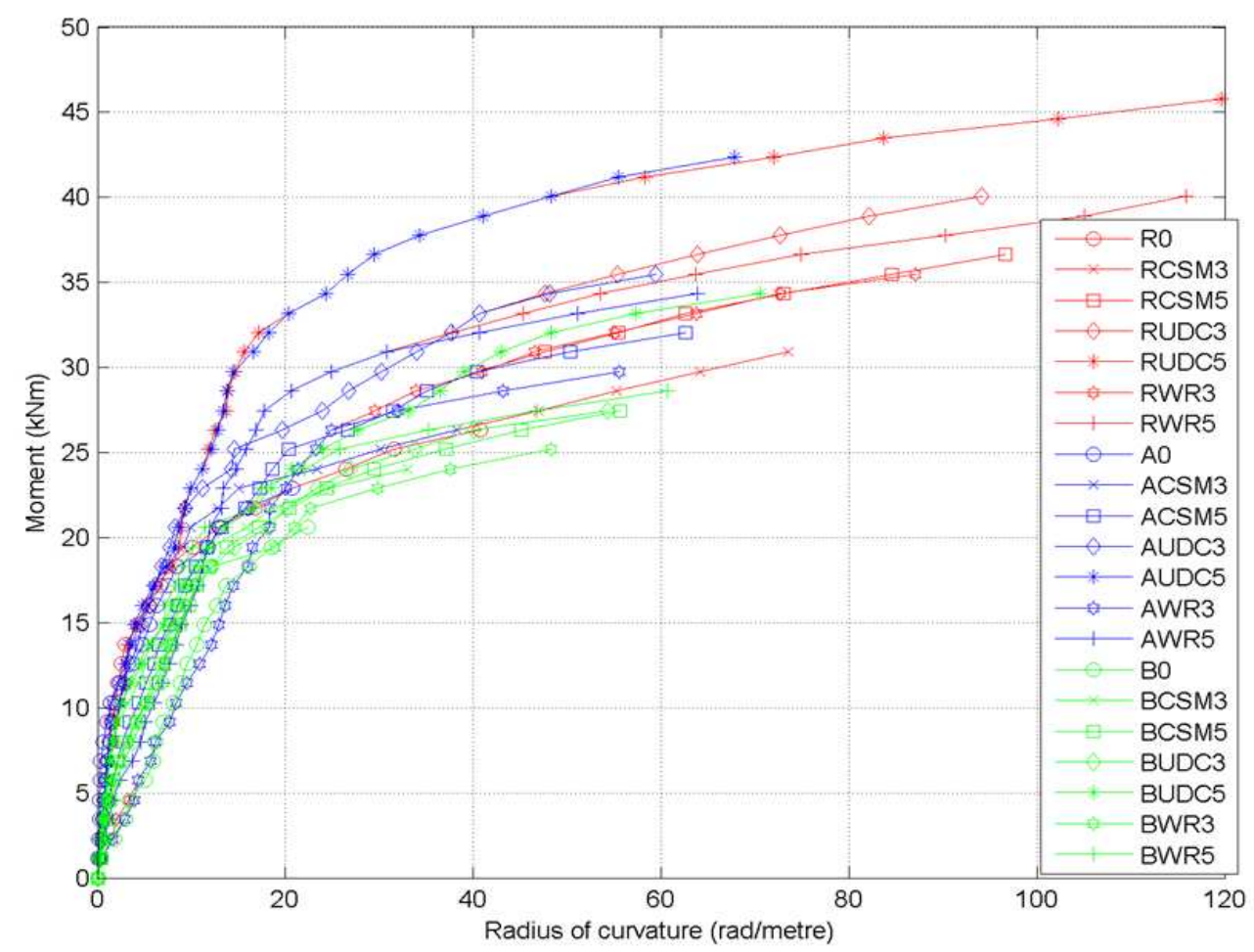

Fig. 8: Moment-curvature trace for all specimens

The load-deflection behaviour of the test specimens are shown in Fig. 9. Increasing corrosion damage resulted in poorer flexural performance of beams. The Bseries beams which sustained $25 \%$ corrosion damage showed a poorer performance when compared to the Aseries beams with $10 \%$ corrosion damage.

At $10 \%$ corrosion damage, the behaviour of the beams was almost identical to that of undamaged ones at the initial stages, although the strength levels are lower for corroded beams. At $25 \%$ corrosion damage, beams show signs of their weakness early in the load deflection curves. This means that the damage sustained by the beam due to corrosion greater than $10 \%$ results in more rapid loss of strength for the beam. It might indicate a non-linear, asymptotic decrease in strength of beams proportional to the inverse of remaining area of steel.

The application of FRP plating increases the strength levels of undamaged beams and restores the lost strength for corrosion damaged beams. The level of restoration in strength is affected by the thickness of FRP applied-higher thickness of FRP plating resulting better load carrying capacity. The stiffness aspect of FRP plated beams increased from that of corresponding unplated beams - which meant higher EI value and lower deflection/ curvature for beams plated with FRP when compared to unplated beams.
The curves indicate that UDCFRP provides the most effective plating mechanism for beams. The other FRP plate of CSM and WR contributed to the restoration in strength of corrosion damaged beams, although not to the levels achieved using UDCFRP. This result indicates that the orientation of fibres in FRP plated beams is a significant parameter to achieve effective restoration from corrosion damage for a given thickness of FRP plating.

Basics of ANFIS: ANFIS as a modelling system consists of three distinct segments: i) the input parameters and membership functions, ii) the adaptive neuro-fuzzy inferencing system, iii) the output parameter and the defuzzifier, if necessary. A schematic view of an ANFIS object is shown in Fig. 10.

Each of the input parameters is associated with countable number of membership functions. These membership functions are used to fuzzify the input data and evaluate the membership of the given crisp input value.

The ANFIS block receives the membership values associated with each membership function and does a series of fuzzy computations. The fuzzy computations are carried out using fuzzy rules, which represent decision making criteria. 


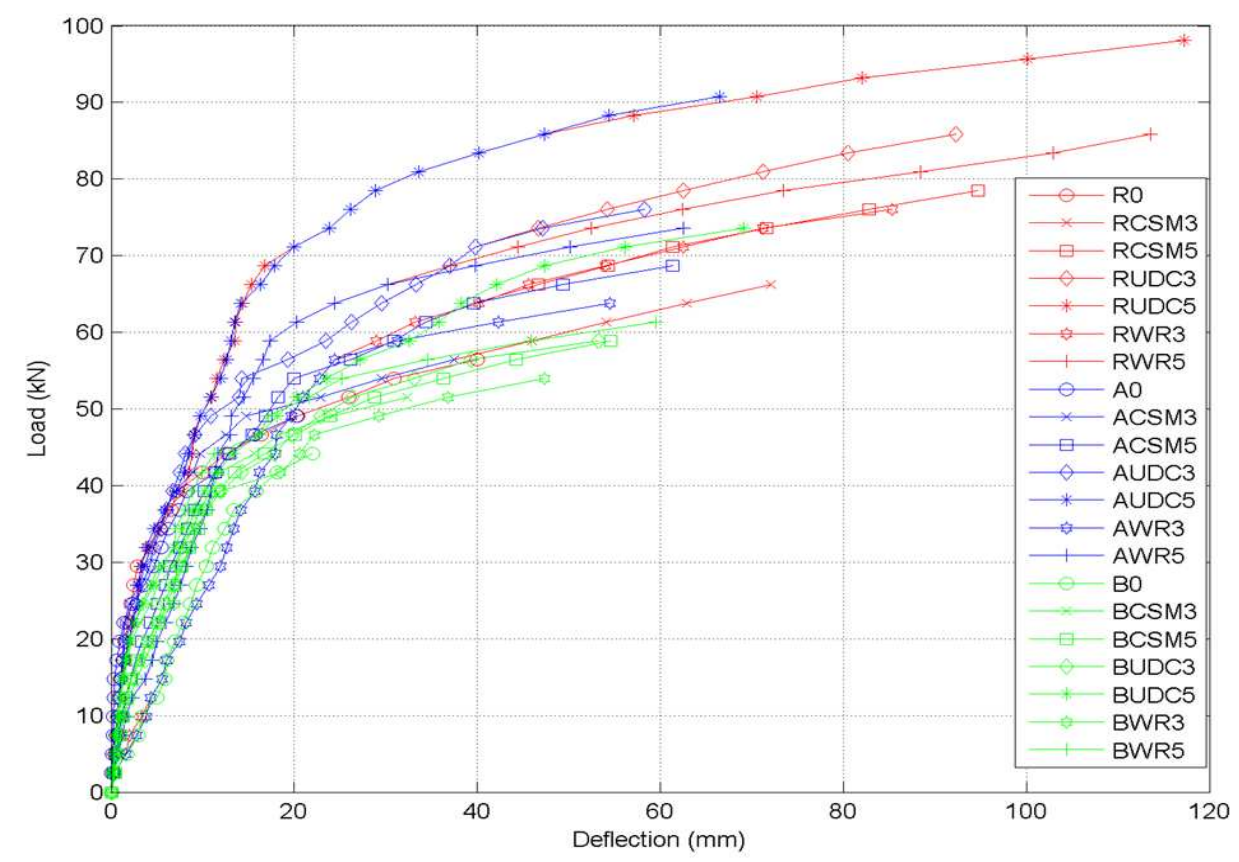

Fig. 9: Load-deflection curves for all specimens

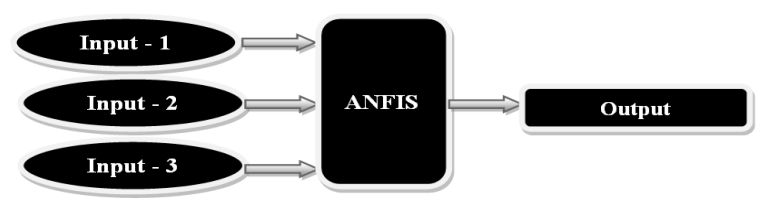

Fig. 10: Schematic View of ANFIS

The number of fuzzy rules built into the ANFIS system is equal to the multiple of the number of rules associated with each input parameter. Hence, the rule based evaluation engine computes the possible output value and communicates it to the output block. The output might sometimes be fuzzy, in the form of a qualitative statement or crisp, in the form of a concise numerical value. If a crisp output is required, the output block translates the fuzzy value into equivalent crisp value.

During training, the parameters associated with the membership functions are fine tuned using Neural Networks, which eliminates the burden of manually tuning up the membership functions.

The present implementation of ANFIS model was carried out using the fuzzy logic toolbox available in MATLAB software. The implementation permits choosing the number and type of membership function associated with each input and the number of epochs required for training the ANFIS. The generation of the network and tuning of the network parameters to match the expected target values are fully automated, with provision for supplying a test data set along with the training set to avoid over-fitting the inference system.

Development of ANFIS model: The ANFIS model is capable of predicting only one output parameter, although the input parameters may be many in number. Hence, each prediction parameter requires a separate ANFIS object to be generated. The input parameters supplied to ANFIS objects are the percentage of corrosion, the type of FRP laminate and the thickness of FRP plate and they remain the same for all objects. ANFIS objects were produced at the rate of one object per parameter for first crack load, first crack deflection, yield load, yield deflection, ultimate load, ultimate deflection, crack width at yield stage, crack width at yield stage, deflection ductility, energy ductility, deflection ductility ratio and energy ductility ratio.

Selection of membership function: Triangular membership function was selected for the input data and constant membership function was selected for the output. The number of membership functions was two per parameter for most of the cases. The choice of membership functions was made by conducting a trial run of the ANFIS objects generated using several alternative functions like trapezoidal membership function, pi membership function, sigmoid membership 
function, generalized bell membership function, Gaussian membership function, S-Shaped membership function. The performance of certain membership functions is good for certain data patterns. The present data showed minimum error levels for triangular input membership function. The output membership function can either be a constant membership function or a linear membership function. For the present data, constant output membership function produced the minimum error. The representation of triangular membership functions is shown in Fig. 11.

Preparation of input data: The input data required for the generation of ANFIS objects were entered into a file called modeldata.mat. The file could hold all the matrices reflecting the twelve tables. Hence, the data loaded into the file serves as a capsule containing the entire input, target and validation data points. The modeldata.mat file is a binary file and could not read or represented as plain text.

Generation of the ANFIS objects: The ANFIS objects were developed by providing the appropriate input, target and training data. A script file called anfisModel.m was developed to generate all the ANFIS objects and then store them all into a file called fisobjects.mat. The script read the input data from modeldata.mat, generated the ANFIS object for given data using the commands genfisl and anfis. The genfisl command generates an initial Fuzzy Inference
System (FIS) based on the training input, training target, number of membership functions per input, names of membership functions for each input and the output membership function. The FIS produced by genfis1 is to be passed into the anfis command to generate the ANFIS object required for predictions.

The anfis command takes the following inputs: the genfis 1 object, maximum number of epochs of training, target value for training, training parameters like initial step size, step down factor, step up factor, display parameters to decide whether to display general ANFIS information, error, step size at each parameter update, final results and the checking data. The checking data, if provided, helps the ANFIS object to avoid over-fitting to the training data and return the ANFIS object which produced the least amount of error for the testing data. Hence, the ANFIS object having desired properties should be ready on running the anfis command.

Errors in ANFIS prediction and validation: The ANFIS objects developed for predicting various parameters related to the GFRP strengthened high strength concrete beams predicted data with varying degrees of errors. The errors associated with the final ANFIS objects are shown in Table 4. The errors displayed in the tables, called Root Mean Squared Percentage Errors, were calculated as the root mean squared error for the parameter divided by the mean of the parametric values and converted to percentage.

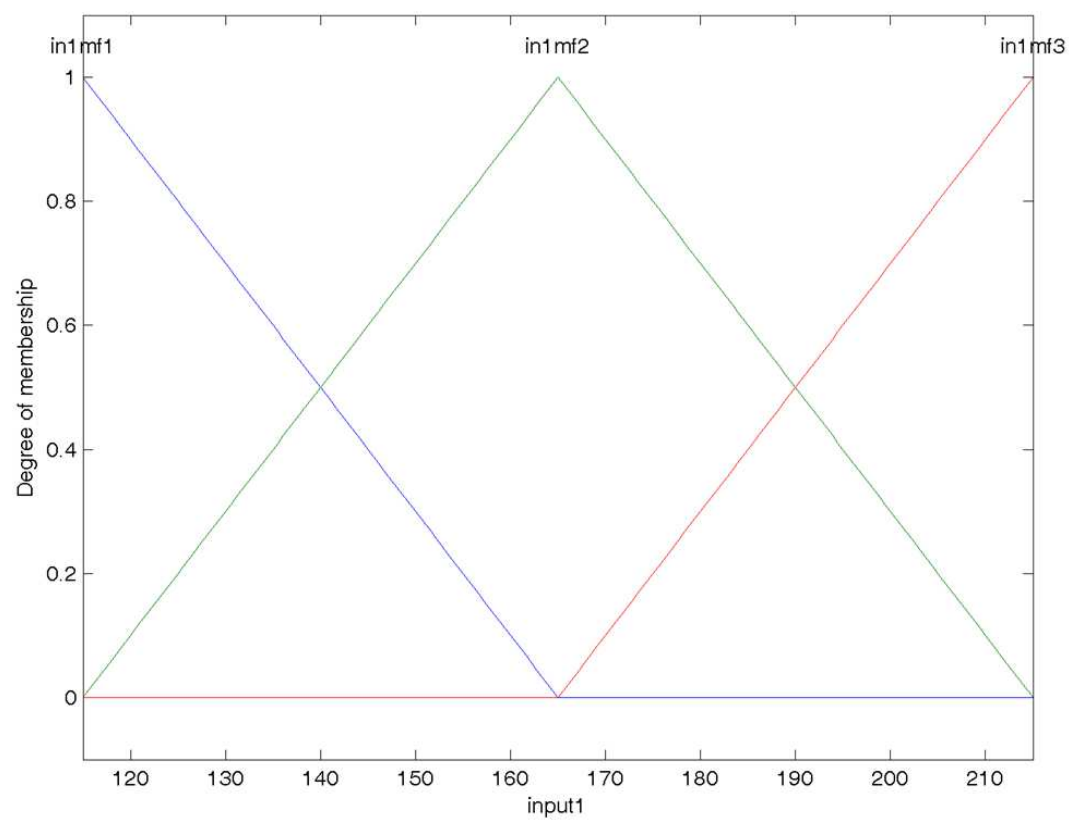

Fig. 11: Three triangular membership functions 


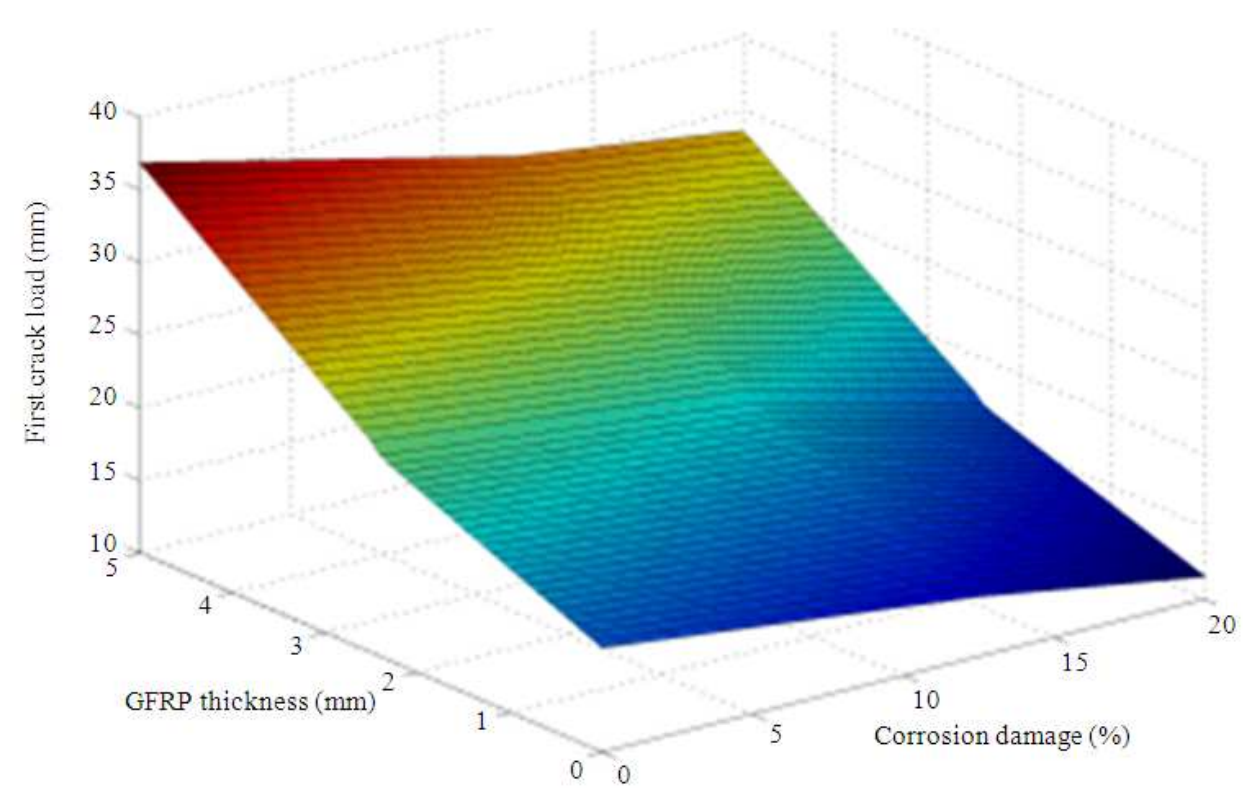

Fig. 12: First crack load: UDC

Table 4: Errors in training and test parameters

\begin{tabular}{llr}
\hline Parameter & $\begin{array}{l}\text { RMS percentage } \\
\text { error in training }\end{array}$ & $\begin{array}{l}\text { RMS percentage } \\
\text { error in testing }\end{array}$ \\
\hline First Crack Load $(\mathrm{kN})$ & 0.0002 & 13.7001 \\
First Crack Deflection $(\mathrm{mm})$ & 0.0002 & 7.5559 \\
Yield Load $(\mathrm{kN})$ & 0.0003 & 7.1711 \\
Yield Deflection $(\mathrm{mm})$ & 0.0002 & 10.0944 \\
Ultimate Load $(\mathrm{kN})$ & 0.0003 & 8.3931 \\
Ultimate Deflection $(\mathrm{mm})$ & 0.0003 & 8.4304 \\
Crack Width at Yield (mm) & 0.0004 & 7.9845 \\
Maximum Crack Width $(\mathrm{mm})$ & 0.0003 & 3.4284 \\
Deflection ductility & 0.0001 & 5.9030 \\
Deflection ductility ratio & 0.0002 & 0.5623 \\
Energy ductility & 0.0002 & 8.6711 \\
Energy ductility Ratio & 0.0002 & 1.3971 \\
\hline
\end{tabular}

The data presented in Table 4 correspond to the errors associated with testing data, which was not used for training the parameters, but only for checking the performance of the ANFIS objects generated using the training data. These error values provide a means for validation of the performance of the ANFIS objects. The Root Mean Square Percentage Error (RMSPE) for training data ranged from $0.0001-0.0003 \%$ and that for testing data ranged from $0.5623-13.7001 \%$. The errors both training and testing data lie within reasonable small limits and hence the model performance is agreeable for prediction purposes.

Using the ANFIS objects for simulation: After validation of the ANFIS objects, they may be used for making predictions for input data at points other than the training and testing points. Points at very close intervals might be used for getting the predictions of ANFIS objects and the results plotted in the form of surfaces. These might help in two ways: (i) getting a rough idea of the values one can obtain from the ANFIS object for given input data, without actually invoking the ANFIS object, ideally suited for preliminary studies and ii) a form of finer validation of the performance of the ANFIS objects at points other than the training and testing points, which might reveal absurd or unreasonable values if the ANFIS object was improperly trained. The three dimensional surfaces generated for each prediction parameter corresponding to the three types of GFRP wrapping (UDC) are presented in Fig. 12-17.

The simulation surfaces signify the three dimensional visualization of the generalization functions brought about by the ANFIS objects. The simulation surfaces exhibit acceptable values throughout the domain of interest for input data. The absence of any abnormal changes in the slope of the simulation surfaces indicates the ability of the ANFIS objects to smoothly predict the values at points other than the training points. Hence, the models generated for predicting the properties of GFRP strengthened high strength concrete beams perform well to predict the required properties within the domain of research input data. The stability of the predictions outside the domain of interest are not guaranteed. Hence, the ANFIS objects should not be used for simulation when input parameters fall outside the experimental input range. 


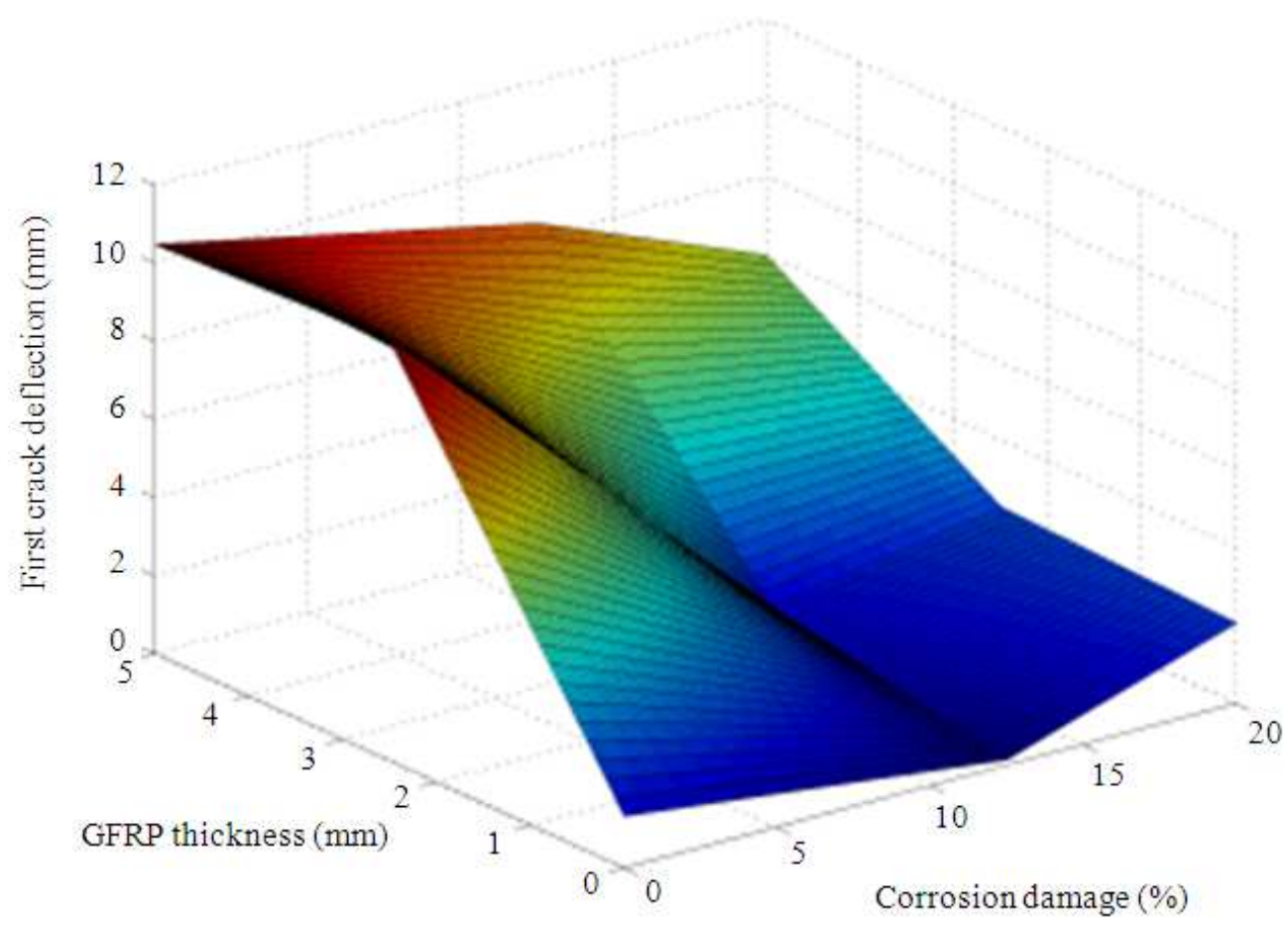

Fig. 13: First Crack Deflection: UDC

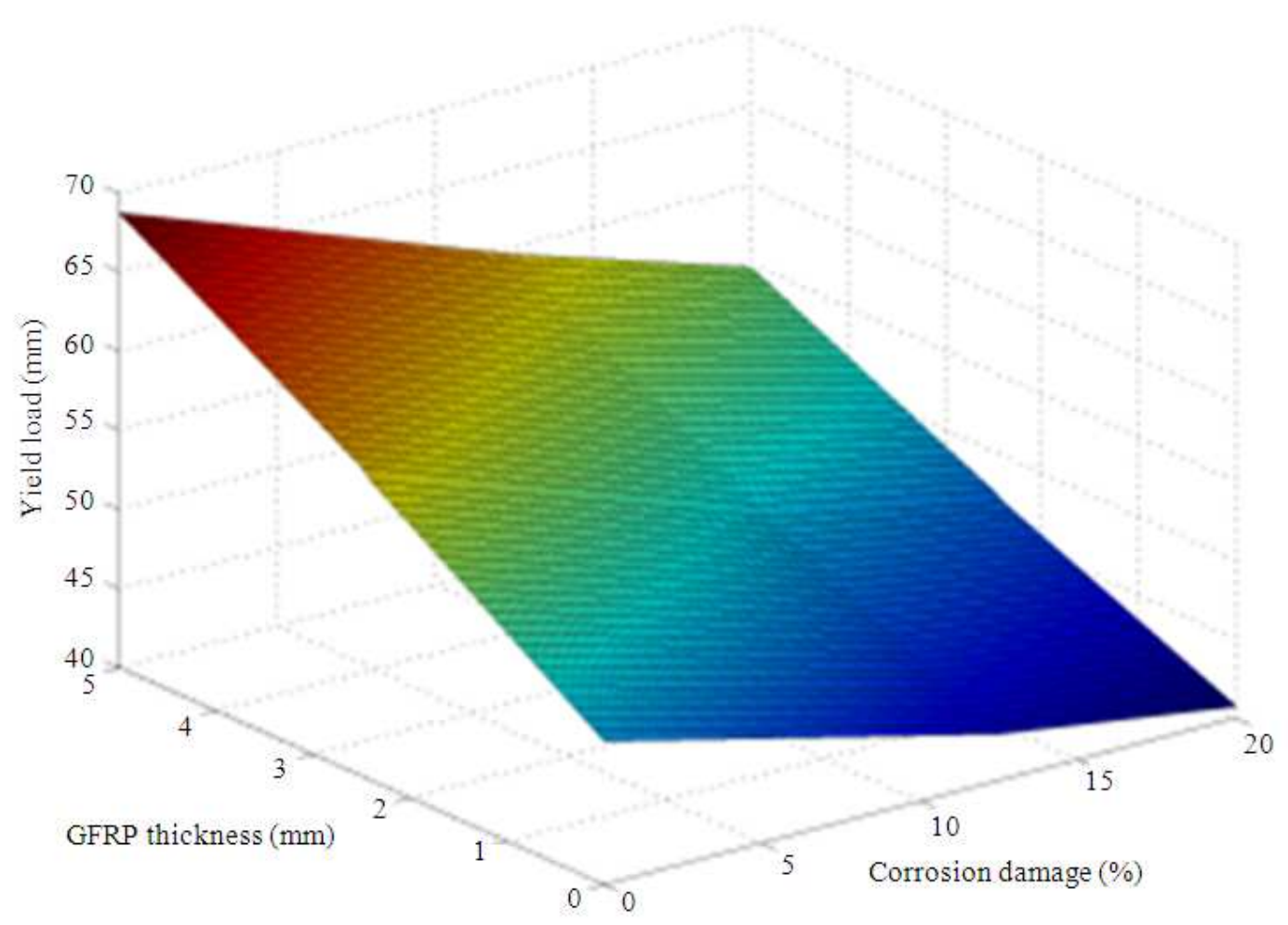

Fig. 14: Yield load: UDC 


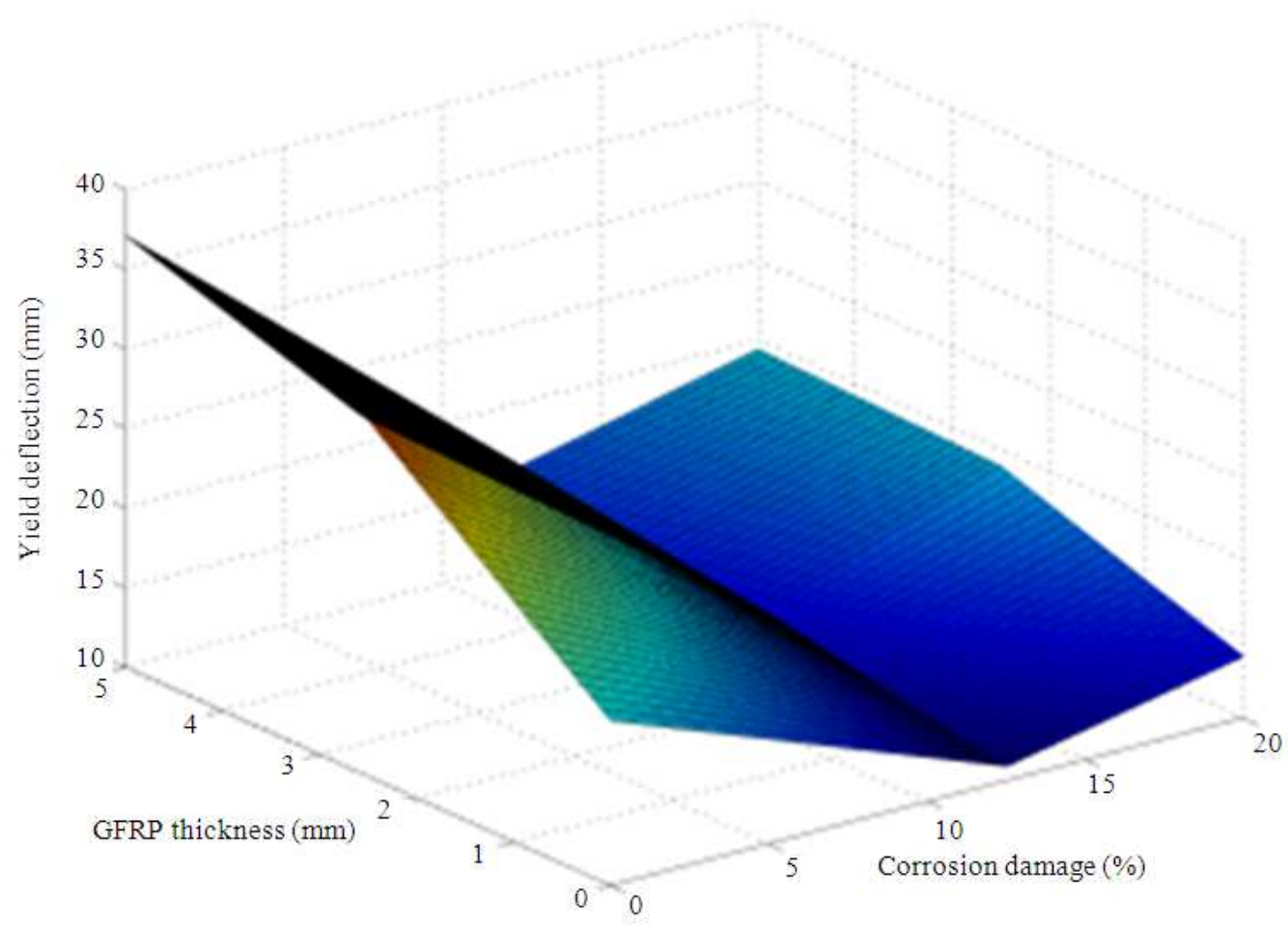

Fig. 15: Yield deflection: UDC

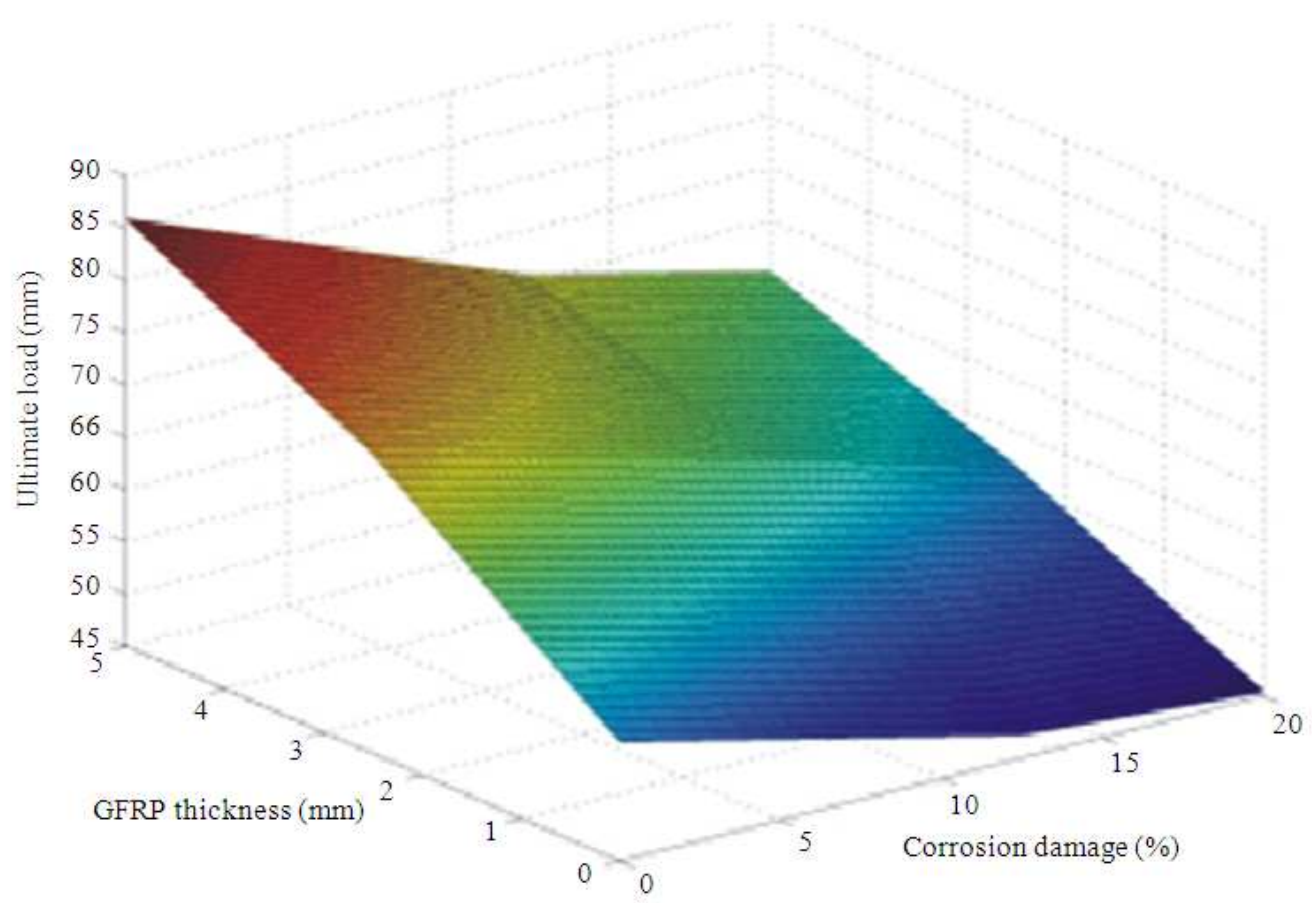

Fig. 16: Ultimate load: UDC 


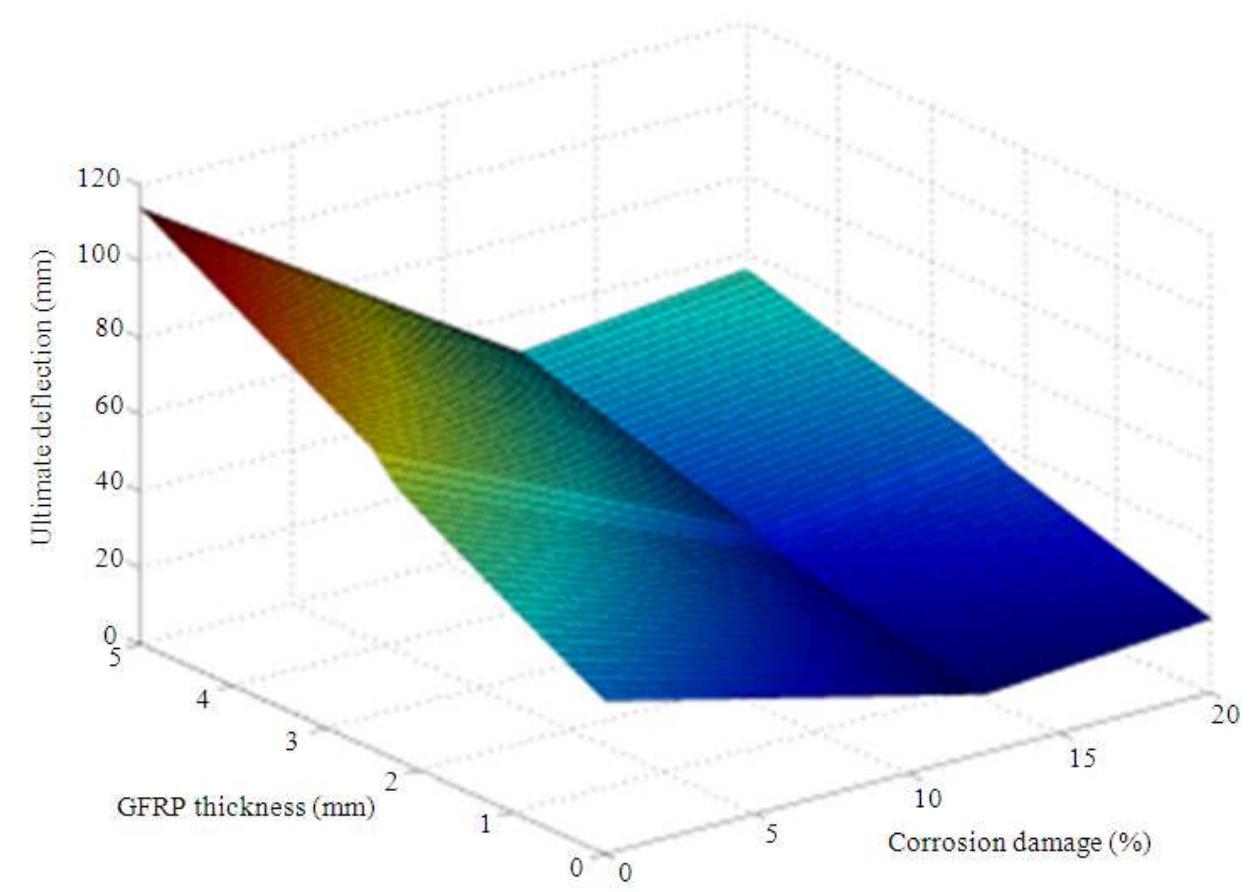

Fig. 17: Ultimate deflection: UDC

\section{CONCLUSION}

The following conclusions are drawn based on the results obtained through experiments and the ANFIS modeling:

- The maximum increase in ultimate load was found to be 34.78 and $30 \%$ for specimens strengthened with UDCGFRP of $5 \mathrm{~mm}$ thickness at 10 and $25 \%$ mass loss

- The reduction in ultimate deflection was found to be 35.48 and $24.97 \%$ for specimens strengthened with UDCGFRP of $5 \mathrm{~mm}$ thickness at 10 and 25\% mass loss

- The increase in deflection ductility was found to be 168 and $49 \%$ at 10 and $25 \%$ mass loss.

- The increase in energy absorption was found to be 165 and $115 \%$ for specimens strengthened with UDCGFRP of $5 \mathrm{~mm}$ thickness at 10 and $25 \%$ mass loss

- Adaptive Neuro-Fuzzy Inference System (ANFIS) model was proposed for predicting the study parameters for input values lying within the range of this experimental study. The Root Mean Squared Percentage Errors (RMSPE) ranged from $0.0001-0.0004 \%$ for training data and 0.5623 $13.7001 \%$ for testing data

\section{REFERENCES}

Almusallam, A.A., A.S. Al-Gahtani, R. Aziz, F.H. Dakhill and A. Rasheeduzzafar, 1996. Effect of reinforcement corrosion on flexural behavior of concrete slabs. J. Mater. Civil Eng., 8: 123-127. DOI: 10.1061/(ASCE)0899-1561(1996)8:3(123)

Al-Sulaimani, G.J., M. Kaleemullah, I.A. Basunbul and A. Razeeduzzafar, 1990. Influence of corrosion and cracking on bond behavior and strength of reinforced concrete members. Struct. J., 87: 220-230.

Andrade, C., M. Alonso and J. Gonzalez, 1990. An initial effort to use the corrosion rate measurements for estimating rebar durability. ASTM., STP-6: 2937. DOI: $10.1520 / \mathrm{STP} 25013 \mathrm{~S}$

Bentur, A., S. Diamond and N.S. Berke, 1997. Steel Corrosion in Concrete: Fundamentals and Civil Engineering Practice. 1st Edn., Taylor and Francis, ISBN: 0419225307, pp: 201.

Hussain, S.E., Rasheeduzzafar, A. Al-Musallam and A.S. Al-Gahtani, 1995. Factors affecting threshold chloride for reinforcement corrosion in concrete. Cem. Conc. Res., 25: 1543-1555. DOI: 10.1016/0008-8846(95)00148-6 
Lee, H.S., F. Tomosawa, Y. Masuda and T. Kage, 1997. Effect of CFRP sheets on flexural strengthening of RC beams damaged by corrosion of tension rebar. Proceedings of 3rd International Symposium on Non Metallic (FRP) Reinforcement for Concrete Structures, Oct. 23-23, Society of Civil Engineers, Tokyo, Japan, pp: 435-442.

Mangat, P.S. and M.S. Elgarf, 1999. Flexural strength of concrete beams with corroding reinforcement. Struct. J., 96: 149-158.

Masoud, S., K. Soudki and T. Topper, 2001. CFRPstrengthened and corroded rc beams under monotonic and fatigue loads. J. Compos. Constr., 5: 228-236. DOI: 10.1061/(ASCE)10900268(2001)5:4(228)
Sherwood, E.G. and K.A. Soudki, 1998a. Durability of concrete beams repaired by carbon fiber reinforced polymer laminates subjected to accelerated rebar corrosion. Proceedings of the CSCE Annual Conference, (CSCE'98), 3b, Halifax, Nava Scoutia, pp: 663-672.

Sherwood, E.G. and K.A. Soudki, 1998b. Repair of Corroded RC beams with carbon FRP sheets. Proceedings of the 5th International Conference on Composites Engineering, Jul. 5-11, Las Veegas, Nevada, pp: 819-20.

Uomoto, T., K. Tsuji and T. Kakizawa, 1984. Deterioration mechanism of concrete structures caused by 3 corrosion of bars. Trans. Jap. Concr. Inst., 6: 163-170. 